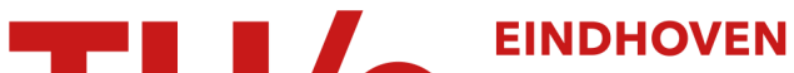 \\ UNIVERSITY OF \\ TECHNOLOGY
}

\section{Block and sub-block boundary strengthening in lath martensite}

\section{Citation for published version (APA):}

Du, C., Hoefnagels, J. P. M., Vaes, R., \& Geers, M. G. D. (2016). Block and sub-block boundary strengthening in lath martensite. Scripta Materialia, 116, 117-121. https://doi.org/10.1016/j.scriptamat.2016.01.043

\section{Document license:}

Unspecified

DOI:

10.1016/j.scriptamat.2016.01.043

Document status and date:

Published: 15/04/2016

\section{Please check the document version of this publication:}

- A submitted manuscript is the version of the article upon submission and before peer-review. There can be important differences between the submitted version and the official published version of record. People interested in the research are advised to contact the author for the final version of the publication, or visit the $\mathrm{DOI}$ to the publisher's website.

- The final author version and the galley proof are versions of the publication after peer review.

- The final published version features the final layout of the paper including the volume, issue and page numbers.

Link to publication

\section{General rights}

Copyright and moral rights for the publications made accessible in the public portal are retained by the authors and/or other copyright owners and it is a condition of accessing publications that users recognise and abide by the legal requirements associated with these rights.

- Users may download and print one copy of any publication from the public portal for the purpose of private study or research.

- You may not further distribute the material or use it for any profit-making activity or commercial gain

- You may freely distribute the URL identifying the publication in the public portal.

If the publication is distributed under the terms of Article $25 \mathrm{fa}$ of the Dutch Copyright Act, indicated by the "Taverne" license above, please follow below link for the End User Agreement:

www.tue.nl/taverne

Take down policy

If you believe that this document breaches copyright please contact us at:

openaccess@tue.nl

providing details and we will investigate your claim. 


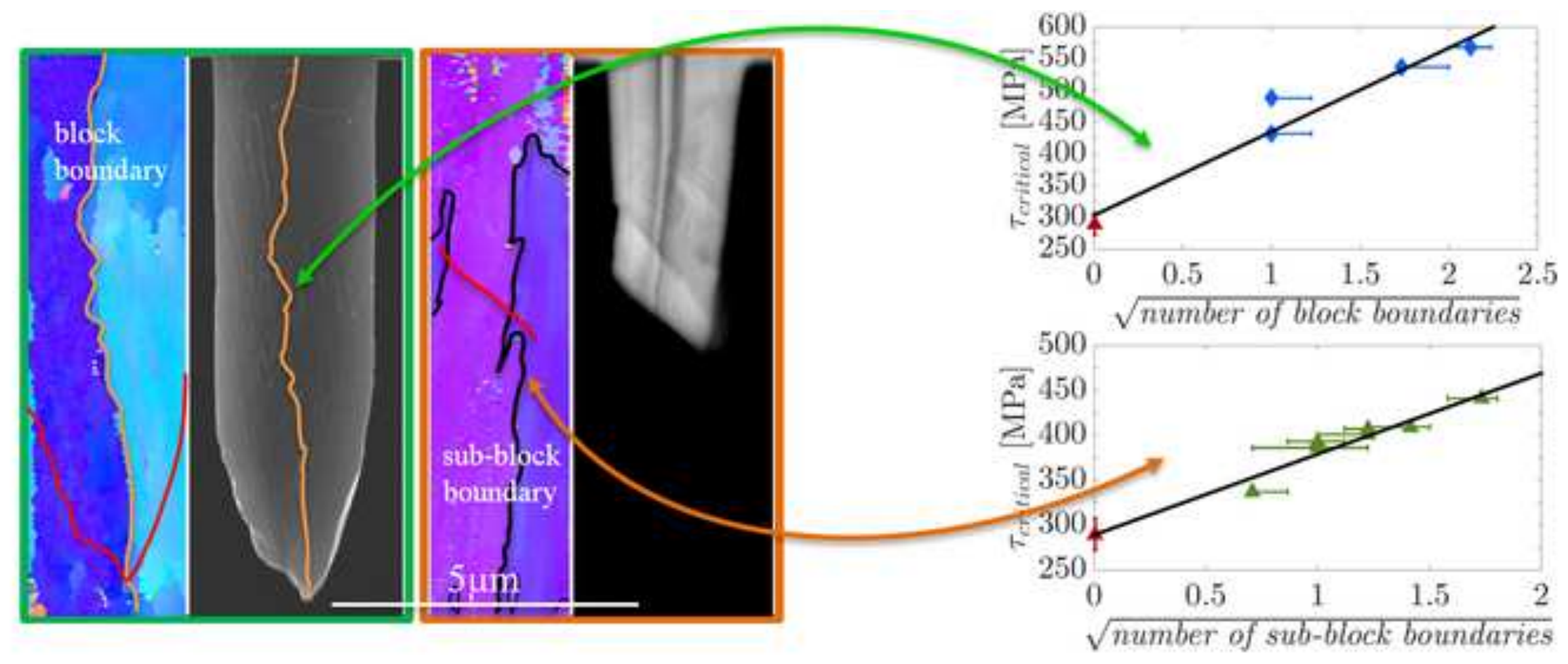




\title{
Block and sub-block boundary strengthening in lath martensite
}

\author{
C. Du, J.P.M. Hoefnagels ${ }^{1}$, R. Vaes, M.G.D. Geers \\ Department of Mechanical Engineering, Eindhoven University of Technology, \\ P.O. Box 513, 5600 MB Eindhoven, The Netherlands
}

\begin{abstract}
Well-defined uniaxial micro-tensile tests were performed on lath martensite single block specimens and multi-block specimens with different number of block boundaries parallel to the loading direction. Detailed slip trace analyses consistently revealed that in the $\{110\}<111>$ slip system with the highest Schmid factor is activated. Both block and subblock boundaries act as barriers to dislocation motion, whereby a Hall-Petch like behavior is observed. Sub-block boundary strengthening appears to be only slightly less effective than block boundary strengthening, even though fracture analyses indicates that dislocation motion can cross sub-block boundaries but not block boundaries.
\end{abstract}

Lath martensite, the most typical morphology of martensite, has high industrial relevance being the prime constituent that elevates the strength in high strength steels, such as dualphase steel, transformation-induced plasticity steel, and quench-partitioning steel. Since decades, research has been carried out on the strengthening mechanisms, which can be categorized into (i) forest dislocation hardening [1,2], (ii) solid solution hardening by alloying elements [2], (iii) precipitation strengthening, e.g., by carbides [2,3], and most importantly (iv) substructure boundary strengthening [4-12]. Indeed, the hierarchical structure, which shows substructures of packets, blocks and sub-blocks emanating from one prior austenite grain, gives lath martensite an abundance of internal boundaries [13]. It was suggested that these boundaries can act as potential barriers to dislocation motion $[2,4,5,6]$.

The mechanical effect of lath martensite boundaries has been investigated in a number of high quality research studies, which can be categorized according to the experimental methodology used: Morito et al. and Zhang et al. performed macroscopic tensile tests and concluded that a Hall-Petch relation holds between the yield strength and the averaged block size $[4,5]$. A more microscopic analysis was carried out by Ohmura et al. through nano- and micro- indentation tests, who concluded (from the ratio between nano- and micro-hardness) that the block structure increases the hardness of martensite $[6,7]$, although no differentiation was made between different types of (packet/block/sub-block) boundaries. Shibata et al. [8,9] performed interesting micro-bending tests, including two single-block

\footnotetext{
${ }^{1}$ Corresponding author. Tel: +3140247 5894, Email address: j.p.m.hoefnagels@tue.nl (J.P.M. Hoefnagels)
} 
specimen tests. From slip trace analysis from the bending side, where the slip activity is highly inhomogeneous due to the complex loading state, they concluded that the block boundaries are the most effective barriers to dislocation motion. The influence of the subblock boundaries present was, however, not investigated in detail. Alternatively, lath martensite has been tested by micro-pillar compression tests, including TEM diffraction analysis, by Ghassemi-Armaki et al. $[10,11]$, who found that single block specimens show perfect elasto-plastic behavior, whereas multiple block specimens show significant strain hardening. These authors acknowledge, however, that the multiple-block specimens may be jeopardized with one or more packet boundaries, making it difficult to determine whether the hardening is due to the block or packet boundaries. Finally, micro-tension tests on lath martensite, including (single-sided) electron-backscattered diffraction (EBSD) analysis, were conducted by Mine et al. [12]. Besides specimens containing multiple packets and even multiple prior austenite grains, also two single-packet specimens were tested with multiple block boundaries over the specimen width, with the boundaries parallel to the loading direction. They concluded that block boundaries can be an effective strengthening mechanism, although the contribution of the sub-block boundaries was again not studied. In general, unclarity persists on the precise and distinct role of block and sub-block boundaries in terms of the resulting strengthening mechanism. Therefore, to be able to directly expose the most relevant microscopic deformation mechanisms, reliable experiments under welldefined loading conditions are required, testing single-packet specimens with and without a single, straight block boundary as well as single-block specimens with a different number of sub-block boundaries. The mechanical tests should be accompanied by a detailed orientation analysis from at least two sides to confirm the 3D orientation(s) throughout the specimen volume.

In this study, we perform uniaxial micro-tensile tests, using a home-built nano-force tensile tester [14], of lath martensite specimens consisting of either a single packet or single block with a range of, respectively, block or sub-block boundaries. The methodology involves the following steps: (i) fabrication of a wedge shape from a lath martensite sheet by grinding/polishing/electro-chemical etching, (ii) careful selection of the specimen location based on large-area EBSD maps, (iii) focused ion beam (FIB) milling of the micro-tensile specimens (Fig. 1(a)), (iv) detailed top- and bottom-side EBSD analysis of each specimen (Figs. 2,3,4), (v) uniaxial tensile tests with highly accurate specimen alignment and forceand displacement measurement (Fig. 1(b,c)) under (vi) in-situ optical microscopy enabling microscopic slip trace analysis[15]. We will show that not only block boundaries but also sub-block boundaries play a key role in lath martensite strengthening. 


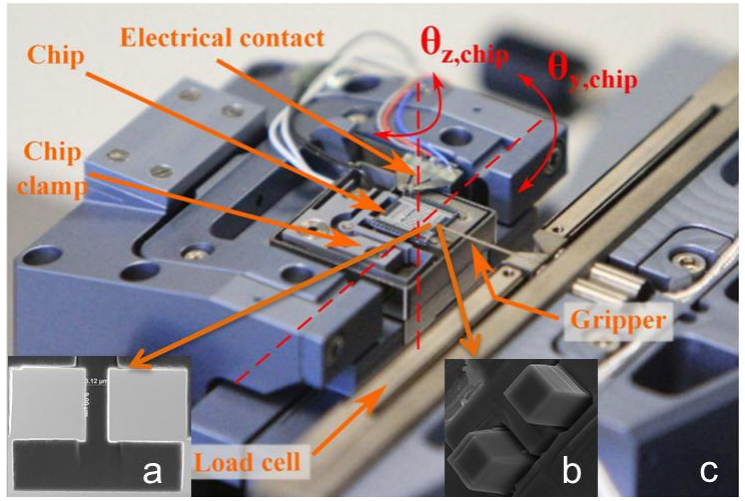

Fig.1. (a) Top-view image of a uniaxial-tension specimen with a gauge size of $9 \times 3.1 \times 2.5$ $\mu m^{3}$ [15]. (b) The 'two-teeth' gripper to load the specimens. (c) The home-built nanoforce tensile stage, equipped with high-precision specimen alignment $(<0.1 \mathrm{mrad}$ angular alignment and near-perfect co-linearity), drift-compensated precision force measurement (from $0.07 \mu \mathrm{N}$ to $250 \mathrm{mN}$ ), and digital image correlation-based displacement measurement ( $<6 \mathrm{~nm}$ reproducibility) [14].

The lath martensite specimens $(0.092 \mathrm{C}-1.68 \mathrm{Mn}-0.24 \mathrm{Si}-0.57 \mathrm{Cr})$ were produced by homogenization at austenite temperature in a vacuum furnace, followed by water quenching. Most specimens were discarded for analysis because detailed EBSD analysis at both specimen sides showed that the microstructure was not homogeneous through the thickness. For a first batch of specimens, with an average block size smaller than the specimen size, only one specimen was identified with the target microstructure and desired orientation. Therefore, a second batch of specimens with larger block size was produced with more suitable specimens. The single specimen retained from the first batch is first discussed since it very properly reveals the role of the block boundary, see Fig. 2 .

The EBSD maps of the top and bottom side (Fig. 2(a,b)) confirm that the block boundary is approximately in the middle of the specimen and constant through the thickness. The inverse pole figures of the top and bottom sides are shown in Figs. 2(e)-(h), which demonstrate the uniformity of the microstructure within the specimens. The block boundary was confirmed to be a high angle boundary with 60 degrees misorientation. From the austenite-to-martensite transformation-orientation relationship it is known that the block (and sub-block) boundaries form at a $\{111\}$ prior austenite plane, i.e. parallel to a $\{110\}$ martensite plane, therefore, the dots (red circles) on the peripheral in the $\{110\}$ plots (Figs. $2(e, f))$ confirm that the block boundary is perpendicular to the specimen surface. In all (further) pole figures, solid black circles highlight the slip direction and slip plane of the $\{110\}<111>$ slip system with the highest Schmid factor. The marked slip traces (dotted 
lines) in Figs. 2(d) is in good agreement with the slip system with highest Schmid factor, considering the significant crystal rotation upon fracture. More convincing evidence for single slip system activation is shown below for the single block specimens. Interestingly, the fracture surfaces join exactly at the block boundary in the middle, where the slip systems are interrupted. This is the first direct evidence that block boundaries in lath martensite act as barriers to dislocation motion for the case where the activated slip system is crossed by a block boundary.
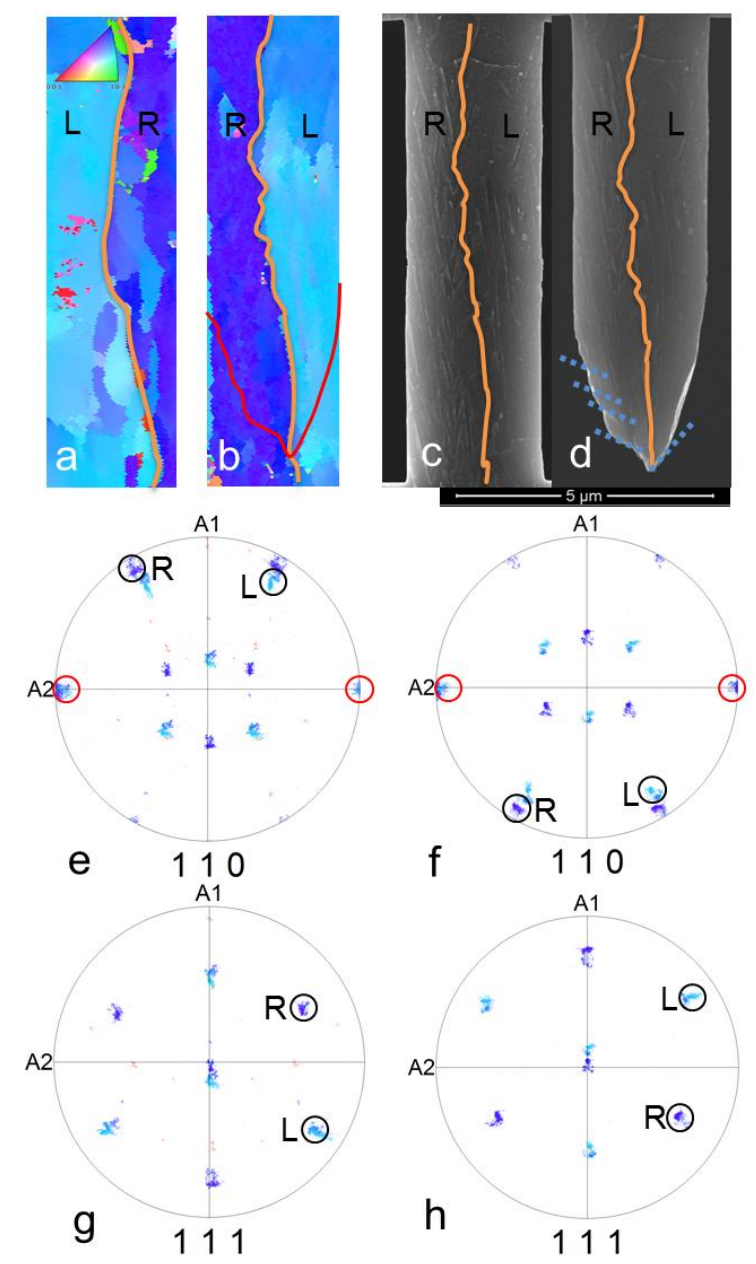

Fig.2. EBSD maps of a bi-block specimen from front (a) and backside (b). Backside SEM image before (c) and after (d) fracture. (e-h) the $\{110\}$ and $\{111\}$ pole figures of the front side $(e, g)$ and backside $(f, h)$. The circles indicate the observed slip planes of both the left block $(L)$ and the right block $(R)$.

From the second batch of specimens, a series of specimens with different configurations of boundaries are produced and tested: specimens with no block boundaries (i.e. single block specimens), 1 parallel block boundary and multiple parallel block boundaries. In Fig. 3(a,b), 
two examples of specimens with multiple block boundaries are shown. In the case of few block boundaries (Fig. 3(a)), with large boundary-free regions at the specimen sides, the fracture propagates from both specimen sides and stops at the first block boundary, similar to the single block boundary case. However, between the two block boundaries, the slip activity is more complex due to the induced loading constraints, resulting in a jagged fracture surface. The same phenomenon is also observed when the boundary-free regions at the specimen sides are small, due to the presence of many block boundaries (Fig. 3(b)). Due to the fact that the dislocations cannot propagate through block boundaries, a zig-zag fracture surface is formed with multiple peaks (black line in Fig. 3(b)), in agreement with the block boundaries.

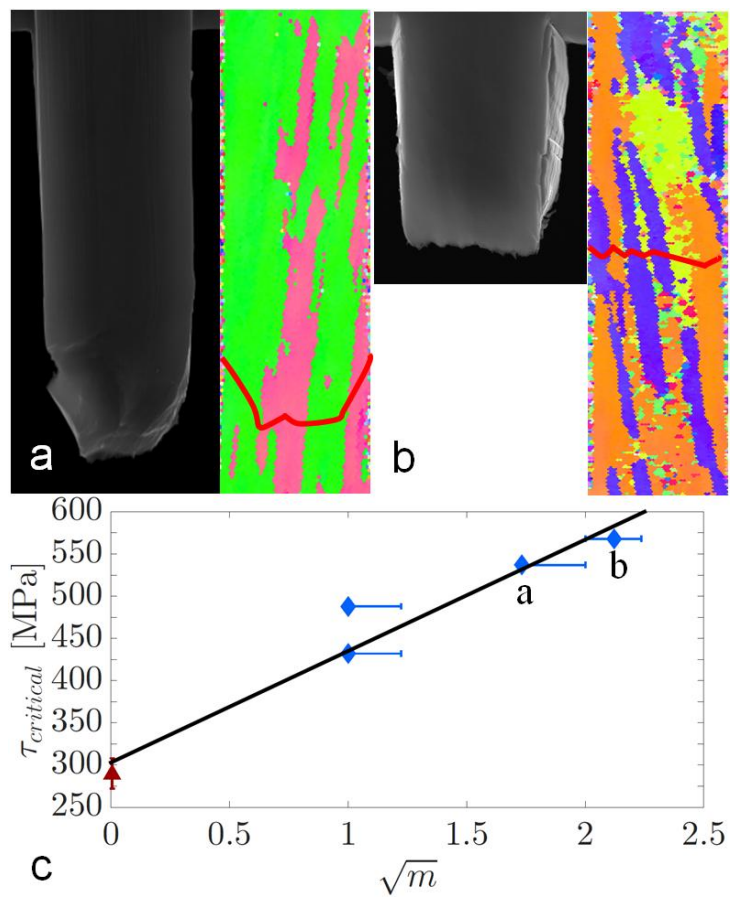

Fig.3. The second batch specimens: $(a, b)$ for both specimens, marked in (c), the fracture surface (left) and EBSD map (right) are shown. The length of undeformed samples is $9 \mu m$. Red curves mark the fracture traces in the EBSD maps. (c) $\tau_{\text {critical }}$ (the fracture stress multiplied with the highest Schmid factor of the largest block) versus $\sqrt{m}$, where the error bars reflect (an estimation of) the uncertainty in the number of block boundaries, $m$. The data point at $\sqrt{m}=0$ in red corresponds to the strength without block and sub-block boundaries as obtained from the offset in Fig. 4(e).

To analyze the strengthening caused by block boundaries, Fig. 3(c) shows the critical stress, $\tau_{\text {critical }}$, (i.e. the fracture stress multiplied with the highest Schmid factor of the 
largest block) versus the square root of the number of block boundaries, $\sqrt{m}$, where $m$ is the average number of block boundaries observed at both side.

Interestingly, Fig. 3(c) shows that $\tau_{\text {critical }}$ increases linearly with $\sqrt{m}$. This linear relationship provides microscopic evidence of a Hall-Petch type relationship for block boundaries, as already suggested in $[4,5]$. Note that only clean multi-block specimens have been included in Fig. 3(c), i.e. all of these specimens are free of sub-block boundaries, except the specimen with the lowest $\tau_{\text {critical }}$ where one sub-block boundary is observed only on the top right side. This specimen would have had an even lower $\tau_{\text {critical }}$ without this sub-block boundary. Therefore, the observed strengthening cannot be attributed to the presence of sub-block boundaries, but must be caused by the block boundaries. The slope of the linear fit in Fig. 3(c) is 132 [MPa], including all inaccuracies. This value cannot directly be compared to Hall-Petch constants for bulk lath martensite, because the fraction of 'grains' in our micro-specimens that are cut off at the side by the free surface is significant.

Next, the strengthening effect of sub-block boundaries is investigated. Two examples of single block specimens from the same packet and with the same sub-blocks are shown in Figs. $4(a, b)$. The misorientation between the sub-blocks is $\sim 8$ degrees, i.e. a small angle boundary. Both fracture surfaces and slip traces are continuous across the sub-block boundary and no difference can be observed in the two sub-blocks due to the small missorientation. Both samples in Fig. 4(a,b) reveal the same slip trace and fracture surface, which demonstrates the reproducibility of this testing method as well as the consistent activation of micro-mechanical mechanisms. The $\{110\}<111>$ system with the highest Schmid factor is again activated in both sub-blocks. 

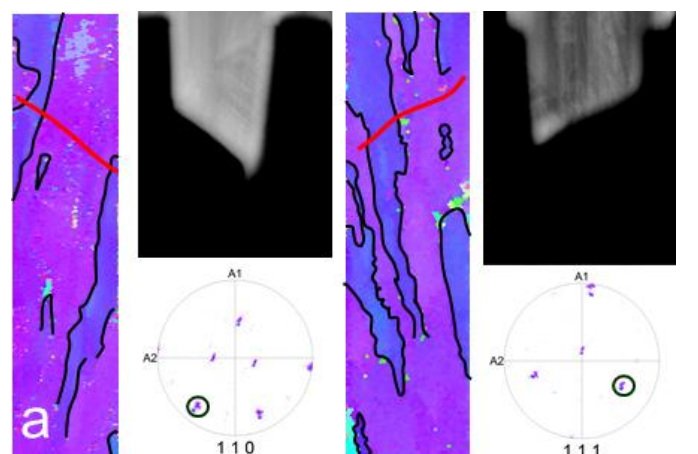

Fig.4. (a-d) the EBSD map and the BSE fracture image of the front (left) and back (right) side and the $\{110\}$ and $\{111\}$ pole figures for each specimen, marked in (e). The length of undeformed samples is $9 \mu \mathrm{m}$. (e) $\tau_{\text {critical }}$ versus the square root of number of sub-block boundaries $\sqrt{n}$, where the error bars reflect (an estimation of) the uncertainty in the number of sub-block boundaries, $n$. The fracture traces and subblock boundaries are marked with, respectively, red and black curves in the EBSD maps.

Two other single block specimens are shown in Fig. 4(c) and Fig. 4(d). Again, analysis shows that the slip system of the $\{110\}<111>$ family with the highest Schmid factor is active. The slip traces are almost the same in the two sub-blocks, while the fracture surfaces cross the sub-block boundaries, respectively. The specimen in Fig. 4(d) contains more sub-block boundaries in the upper part of the specimen than in the bottom part. Perhaps not surprisingly, the specimen fractures at the bottom part where it is less heterogeneous, which confirms the sub-block boundary strengthening mechanism.

For the single block specimens, $\tau_{\text {critical }}$ is plotted as a function of the square root of the number of subblock boundaries, $n$, in Fig. 4(e), where $n$ is calculated similarly to $m$ in Fig. 3(c). The main difference between the four specimens shown in Fig. 4 lies in the number of sub-block boundaries crossed by the fracture surface. The more sub-block boundaries that are crossed by the fracture surface, the stronger the specimen. Similar to the strengthening mechanism of block boundaries, $\tau_{\text {critical }}$ increases linearly with $\sqrt{n}$, with a slope of $90 \mathrm{MPa}$. 

strengthening. Although the slopes of Fig. 3(c) and 4(e) are subject to experimental and microstructural uncertainties, the smaller slope in Fig. 4(e) indicates that strengthening by sub-block boundaries is only somewhat less effective. This in-depth uniaxial tension analysis directly proves that the strengthening effect of sub-block boundaries is highly important, which is in sharp contrast to the statement in Ref. [8] that the sub-block boundaries have a negligible contribution to the macroscopic strength of lath martensite.

Interestingly, yet qualitative, in-situ TEM observations in [16] showed that dislocations pile up at a low angle boundary followed by transmission through it. This can explain why (almost) all fracture surfaces of the single-block specimens show a single straight fracture surface spanning the complete cross-section. It was also suggested in [16], from the sudden disappearance of dislocations at a block boundary, that dislocations 'reflect' and then glide along the high-angle boundaries (to the free surface). If dislocations can indeed glide along a block boundary instead of cutting through the boundary, this may explain why the fracture surfaces of two adjacent blocks join exactly at the block boundary, as shown most clearly in Fig.2, and why the fracture surface for multi-block specimens is jagged.

In summary, uniaxial micro-tensile tests were performed on lath martensite specimens with a different number of block boundaries parallel to the loading direction and single-block specimens with a different number of sub-block boundaries. For the single-block specimens, the observed slip traces match the slip system with the highest Schmid factor. Both the block and sub-block boundaries act as a barrier for dislocation motion, clearly strengthening the material. For both block and sub-block boundaries, a Hall-Petch type relationship was found between $\tau_{\text {critical }}$ and the number of boundaries, and the strengthening effect of subblock boundaries appears to be only slightly less effective as that of block boundaries. For multi-block specimens, the fracture surface joins at the block boundary, indicating that the fracture cannot propagate across block boundaries. This is in contrast to sub-block boundaries for which a single straight fracture surface over the cross-section is consistently identified.

\section{Acknowledgements}

This research was carried out under project number M22.2.11424 in the framework of the Research Program of the Materials innovation institute (M2i) (www.m2i.nl). 


\section{References}

[1] S. Takaki, K. Ngo-huynh, N. Nakada, T. Tuchiyama, ISIJ Int. 52 (2012), 710-716.

[2] G. Krauss, Mater. Sci. Eng. A 273-275 (1999) 40-57.

[3] T. Ohmura, T. Hara, K, Tsuzaki, Scr. Mater. 49 (2003) 1157-1162.

[4] S. Morito, H. Yoshida, T. Maki, X. Huang, Mater. Sci. Eng A 438-440 (2006) 237-240.

[5] C. Zhang, Q. Wang, J. Ren, R. Li, M. Wang, F. Zhang, K. Sun, Mater. Sci. Eng A 534 (2012) 339-346.

[6] T. Ohmura, T. Hara, K. Tsuzaki, J. Mater, Res., 18 (2003) 1465-1470.

[7] T. Ohmura, T. Hara, K, Tsuzaki, Scr. Mater. 49 (2003) 1157-1162.

[8] A. Shibata, T. Nagoshi, M. Sone, S. Morito, Y. Higo, Mater. Sci. Eng A 527 (2010) 7538-7544.

[9] A. Shibata, T. Nagoshi, M. Sone, S. Morito, Y. Higo, J. Alloy. Compd. 577 (2013) S555S558.

[10] H. Ghassemi-Armaki, P. Chen, S. Bhat, S. Sadagopan, S. Kumar, A. Bower, Acta Mater. 61 (2013) 3640-3652.

[11] H. Ghassemi-Armaki, R. Maass, S.P. Bhat, S.Sriram, J.R. Greer, K.S.Kumar, , Acta Mater. 62 (2014) 197-211.

[12] Y. Mine, K. Hirashita H. Takashima, M. Matsuda, K. Takashima, Mater. Sci. Eng A 560 (2013) 535-544.

[13] S. Morito, H. Tanaka, R. Konishi, T. Furuhara, T. Maki, Acta Mater. 51 (2003) 17891799.

[14] L.J. Bergers, J.P.M. Hoefnagels, M.G.D. Geers, J. Phys. D: Appl. Phys., 47 (2014).

[15] C. Du, J.P.M. Hoefnagels, L.J.Bergers, M.G.D. Geers, submitted for publication.

[16] T. Ohmura, A.M. Minor, E.A. Stach, J.W.Morris, J. Mater. Res., 19 (2004). 